Macromolecular Nanotechnology

\title{
Effect of sepiolite organomodification on the performance of PCL/sepiolite nanocomposites
}

\author{
Marija S. Nikolic ${ }^{\mathrm{a}, *}$, Rada Petrovic ${ }^{\mathrm{a}}$, Djordje Veljovic ${ }^{\mathrm{a}}$, Vladan Cosovic ${ }^{\mathrm{b}}$, Nadezda Stankovic ${ }^{\mathrm{c}}$, \\ Jasna Djonlagic ${ }^{\mathrm{a}}$ \\ ${ }^{\text {a }}$ Faculty of Technology and Metallurgy, University of Belgrade, Karnegijeva 4, Belgrade, Serbia \\ ${ }^{\mathrm{b}}$ Institute of Chemistry, Technology and Metallurgy, University of Belgrade, Njegoseva 12, Belgrade, Serbia \\ ${ }^{\mathrm{c}}$ Vinca Institute of Nuclear Sciences, University of Belgrade, P.O. Box 522, Belgrade, Serbia
}

\section{A R T I C L E I N F O}

\section{Keywords:}

Sepiolite

Poly( $\varepsilon$-caprolactone)

Biodegradable

Nanocomposite

\begin{abstract}
A B S T R A C T
Poly( $\varepsilon$-caprolactone) (PCL) based nanocomposites with unmodified and organomodified sepiolites were prepared by solution casting method. The sepiolites were modified with short (3-mercaptopropyl)trimethoxysilane (SEP-SI) by using covalent grafting or with long hexadecylamine (SEP-HDA) by using ionic exchange. In order to reveal the influence of the organomodification on the nanoclay dispersion and the properties of the nanocomposites XRD, DSC, TG, SEM, TEM, optical microscopy, melt rheology and dynamic-mechanical analyses were performed. A better dispersion was achieved when organomodified sepiolites instead of native ones were used as fillers. As deduced from the melt rheology data, by analysis of the Cole-Cole plots, the best dispersion was obtained for SEP-SI nanoclay. The thermal stability was not improved, however in the initial stages of the thermo-oxidative degradation a delay in the weight loss was observed for nanocomposites with organomodified sepiolites. The mechanical properties of the nanocomposites were improved in comparison to PCL, particularly for those with modified sepiolites. In terms of mechanical properties the use of sepiolite modified with HDA gave the best results, as a consequence of better interaction between longer alkyl hydrophobic part of the organic modificator and the hydrophobic PCL matrix.
\end{abstract}

\section{Introduction}

The environmental protection awareness and growing needs for new materials in biomedicine led to progress in the biodegradable polymers research. One of the most promising biodegradable aliphatic polyester is the poly( $\varepsilon$-caprolactone) (PCL), which is suitable for different applications - from custom materials to pharmacy [1]. It is a semi-crystalline polymer which has low melting and glass transition temperatures and favorable rheological properties for processing from the melt. Since PCL has a great potential for use as a biodegradable polymer in agriculture and as packaging material, the focus of the research efforts is directed toward improvement of its rigidity and barrier properties. Substantial improvements or modifications of the material properties, such as mechanical, thermal or barrier, can be achieved through preparation of nanocomposites $[2,3]$. In order to improve its properties, PCL was used as a matrix in the preparation of nanocomposites with silica [4-6], carbon nanotubes [7], layered clay [8,9], metallic or metal oxide nanoparticles [10-12], etc.

The natural layered silicate clays are probably the most investigated materials, which are used as fillers in nanocomposites. Their natural abundance and developed surface modification procedures are accompanied with substantial properties enhancement, achievable at low nanoclay concentration as a consequence of its high aspect ratio [13-16]. Emerging nanofillers of natural origin belonging to the clay family are the sepiolites, which are fibrous magnesium-silicates. The structural formula of sepiolite is $\mathrm{Si}_{12} \mathrm{O}_{30} \mathrm{Mg}_{8}(\mathrm{OH})_{4}\left(\mathrm{H}_{2} \mathrm{O}\right)_{4} \mathrm{H}_{2} \mathrm{O}$ and it is built of blocks consisting of two tetrahedral silica sheets and central octahedral sheet with magnesium. These blocks are linked along their longitudinal edges and form fine channels with dimensions of $0.37 \times 1.06 \mathrm{~nm}^{2}$ which extend in direction parallel to the length of the fibers. A single sepiolite fiber is approximately $0.2-4 \mu \mathrm{m}$ long, depending on the origin, $10-30 \mathrm{~nm}$ wide and 5-10 nm thick, which corresponds to around nine unit cells in width and three in thickness. The fibers are organized in bundles and the main goal in nanocomposite preparation is to achieve their disaggregation to the level of a single fiber. In comparison to the layered silicates, the specific surface area of the sepiolite is lower for the same aspect ratio; therefore the sepiolite can be dispersed easier in a polymer matrix. In the case of layered

\footnotetext{
* Corresponding author at: Faculty of Technology and Metallurgy, University of Belgrade, Karnegijeva 4, Belgrade, Serbia.

E-mail address: mnikolic@tmf.bg.ac.rs (M.S. Nikolic).
} 
silicates, the surface treatment supports the dispersion of the filler through establishment of favorable filler/polymer interactions. A filler modified with organic coating compatible with polymer is more efficient in creating an interphase $[6,17,18]$ in the nanocomposite, a region of polymer matrix near the filler surface with altered properties compared to the bulk, which further improves the nanocomposite properties. The same principles can be applied in the case of sepiolites. The surface rich in silanol groups makes the sepiolite suitable for diverse surface functionalization and the presence of exchangeable cations makes the basis for its modification through ion exchange reactions. The high density of silanol groups (two Si-OH groups $/ \mathrm{nm}^{2}$ ) [19] at the sepiolite external surface is responsible for the strong hydrogen bonding which sepiolite can establish with hydrophilic polymers. These hydroxyl groups can also be efficiently used for organomodification of sepiolite, usually through organosilane coupling agents, thus making its surface more compatible with hydrophobic polymers. The cation exchange capacity of sepiolite $\left(\sim 30 \mathrm{mmolM}^{+} / 100 \mathrm{~g}\right)$ is lower compared to layered silicates $\left(\sim 120 \mathrm{mmolM}^{+} / 100 \mathrm{~g}\right)$, however organomodification can be also successfully performed through adsorption of ammonium or amine salts [20], thus increasing the sepiolite affinity toward low-polar polymers. Even though it is thought that the unmodified sepiolite can be dispersed more easily than layered clays, the presence of organic modifier on the sepiolite may have an effect on the polymer/ filler interphase creation with specific influence on the nanocomposite overall performance. Also, for the nanocomposites prepared by solution casting the interaction between the solvent and filler can be tuned in order to promote filler dispersion.

There are a few reports on the use of sepiolite as filler in nanocomposites with thermoplastic polymers. Nanocomposites of poly (propylene) (PP) and sepiolite were successfully prepared and mechanical properties improvements were reported for these nanocomposites, albeit only in the presence of compatibilizer which reduced the surface energy and improved the dispersion of sepiolite [21,22]. It was also reported that the surface modification of sepiolite does not promote its dispersion in PP matrix, although it has beneficial effect on thermo-oxidative stability of the polymer matrix, reducing the catalytic activity expressed by the native sepiolite filler [23]. Unmodified sepiolite in polyamide (PA6) matrix showed good reinforcing effect [24], which was attributed to hydrogen boding between the silanol groups of sepiolite and the amide groups of PA6 [25]. However, even better mechanical properties, ascribed to better dispersion state of the filler, were achieved for organosepiolite obtained through cation exchange reactions with different alkylammonium salts [26]. Also, the increment in the properties improvement was proportional to the modifier content [27]. Nanocomposites with polyester matrix were prepared starting from both unmodified and organically modified sepiolites, using mostly melt mixing and in fewer cases solution casting [17,20,28-32]. Early investigations revealed improved properties as a consequence of good dispersibility of untreated sepiolite in PCL, PLA and PBT matrix which was ascribed to hydrogen bonding between silanol groups from sepiolite and carbonyl group in polyester chains [28-30]. There are a few reports dealing with comparison of the properties of biodegradable polyester nanocomposites obtained with unmodified and organically modified sepiolites. The results reported therein for PLA and PHA as matrix materials encourage further investigation of modified sepiolites as a new eco-friendly filler for diverse biodegradable polyesters $[20,31,32]$.

This study compared the performance of PCL nanocomposites obtained from unmodified and two types of modified sepiolites used for the first time in PCL based nanocomposites. The organo-modification was performed in two different ways: by silane grafting using short (3mercaptopropyl)trimethoxysilane and by ionic exchange with longer hexadecylamine. In order to correlate the structure to the achieved properties, the obtained nanocomposites were analyzed and compared in respect to their morphology, melt-rheological behavior, thermal and thermo-oxidative behavior as well as mechanical properties probed by dynamic mechanical analysis.

\section{Experimental}

\subsection{Materials}

Poly( $\varepsilon$-caprolactone) (PCL) was synthesized by ring opening polymerization of $\varepsilon$-caprolactone using stannous octoate as catalyst. The number average molecular weight $\left(M_{\mathrm{n}}\right)$ of PCL was $71,000 \mathrm{~g} / \mathrm{mol}$ and the polydispersity index was 2.11 , as determined by gel-permeation chromatography with polystyrene calibration. Unmodified sepiolite with fibers length of $0.5-2 \mu \mathrm{m}$ and ion exchange capacity of $\sim 30 \mathrm{mmolM}^{+} / 100 \mathrm{~g}$ was supplied from Andrici (Serbia). All solvents used were of analytical grade.

\subsection{Modification of sepiolite}

The modification of sepiolite was performed by: (1) covalent grafting of (3-mercaptopropyl)trimethoxysilane (SEP-SI) and (2) ionic exchange with hexadecylamine (SEP-HDA). The modification procedure for SEP-SI was conducted according to the procedure given in previous reports [33]. Briefly, $12 \mathrm{~g}$ of sepiolite suspended in $300 \mathrm{ml}$ of toluene was refluxed and mechanically stirred for half an hour under dry nitrogen. In the next step $12 \mathrm{ml}$ of mercaptosilane was added dropwise to the suspensions and the mixture was refluxed for $24 \mathrm{~h}$, filtered, washed with toluene and ethanol and then dried under dry nitrogen for $24 \mathrm{~h}$. For the modification with HDA, $5 \mathrm{~g}$ of sepiolite was dispersed in $500 \mathrm{ml}$ of deionized water by probe ultrasonicator SONICS Vibra-Cell for $30 \mathrm{~min}$ (750 W output power, $80 \%$ amplitude, in pulse mode), with a $20 \mathrm{kHz}$ converter and titanium probe with $19 \mathrm{~mm}$ in diameter. The obtained dispersion was heated to $50{ }^{\circ} \mathrm{C}$ and pre-prepared solution of HDA protonated with $\mathrm{HCl}$ was added. The mixture was stirred for $3 \mathrm{~h}$ at $50^{\circ} \mathrm{C}$ and $24 \mathrm{~h}$ at room temperature. The product was filtered and washed until negative $\mathrm{AgNO}_{3}$ test was reached. The modified sepiolite was dried at $60{ }^{\circ} \mathrm{C}$ for $24 \mathrm{~h}$.

\subsection{Preparation of $P C L /$ sepiolite nanocomposites}

The nanocomposites were prepared by film casting from chloroform solution. Three series of nanocomposites were prepared: with unmodified sepiolite (denoted as PCL-SEPx), with silane treated sepiolite (denoted as PCL-SEPSIx) and with HDA treated sepiolite (denoted as PCL-SEPHDAx). In the abbreviation of the samples $x$ refers to the mass fraction of sepiolite in the nanocomposite. Firstly the dispersion of sepiolites in chloroform was prepared by using probe ultrasonicator SONICS Vibra-Cell for $30 \mathrm{~min}$ to promote separation of the sepiolite fibers. In the solution of $1.5 \mathrm{~g}$ of PCL in chloroform a calculated amount of so prepared dispersion was added in order to obtain nanocomposites with 1,3 and $5 \mathrm{wt} \%$ of sepiolite, referring to inorganic part. The suspensions were treated in ultrasonic bath for $30 \mathrm{~min}$, poured into Petri dishes and left at room temperature to solidify through evaporation of the chloroform. The nanocomposite films, with thickness of approximately $200 \mu \mathrm{m}$, were vacuum dried and used for further characterization. Discs and rectangular bars for melt rheology and dynamic mechanical analysis, respectively, were prepared from these films by melt pressing in molds of the desired shape and size at $85^{\circ} \mathrm{C}$.

\subsection{Characterization}

\subsection{1. $X$-ray diffraction (XRD)}

XRD analysis was performed on sepiolite powders and nanocomposites in the form of rectangular solid samples $(19 \mathrm{~mm} \times 12 \mathrm{~mm})$. The XRD spectra were collected at room temperature by using Ultima IV Rigaku diffractometer, equipped with $\mathrm{CuKa}$ radiation $(\lambda=0.15405 \mathrm{~nm})$ and $\mathrm{Ni}$ filter. The generator voltage and current were $40.0 \mathrm{kV}$ and $40.0 \mathrm{~mA}$, respectively. The range of $2-40^{\circ} 2 \theta$ was 

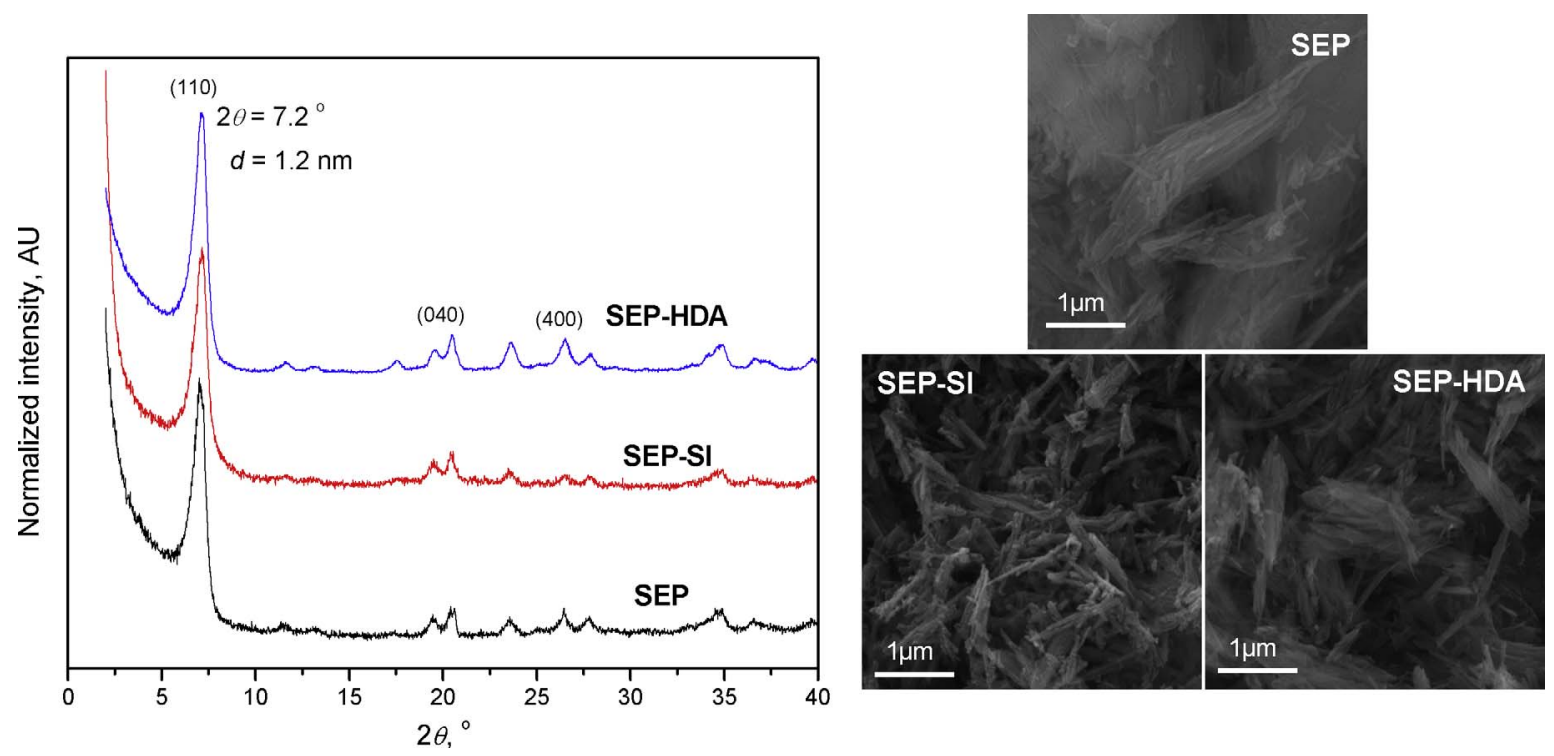

Fig. 1. XRD spectra (left) and SEM images (right) of native and modified sepiolites (magnification 50,000 $\times$ ).

used for all samples in a continuous scan mode with a scanning step size of $0.02^{\circ}$ and at a scan rate of $1 \% \mathrm{~min}$. The degree of crystallinity was calculated as the ratio of areas under the crystalline peaks to the sum of the area of crystalline peaks and the area of amorphous halo, determined by deconvoluting the patterns to the sum of Voight functions (PeakFit ${ }^{\circledR}$ program).

\subsubsection{Scanning electron microscopy (SEM)}

The morphology of native and the modified sepiolites was assessed by scanning electron microscopy on a Tescan MIRA3 field emission gun scanning electron microscope (FESEM), with electron energies of $20 \mathrm{kV}$ under high vacuum. The cryo-fractured surfaces of PCL and its nanocomposites were recorded also by the same instrument and prior to the observation all samples were sputter-coated with an $\mathrm{Au}$ to ensure the surface conductivity. The SEM images were taken at magnification of $50,000 \times$ for the sepiolites and $5000 \times$ and $50,000 \times$ for the nanocomposites.

\subsubsection{Transmission electron microscopy (TEM)}

State of dispersion of sepiolites into the PCL matrix was evaluated by transmission electron microscopy using a JEM-1400 Plus (JEOL) with an acceleration voltage of $120 \mathrm{kV}$. Ultrathin sections of the samples approximately $100 \mathrm{~nm}$ thick were cut using a Leica UC6 Ultramicrotome (Leica Microsystems) and placed on carbon coated copper grids.

\subsubsection{Optical microscopy}

The surface of the PCL and nanocomposite films was examined by using an optical microscope (Leica DM ILM) with reflected light, equipped with a CCD digital camera.

\subsubsection{Differential scanning calorimetry (DSC)}

The thermal properties of the samples were analyzed by differential scanning calorimetry. SDT Q600 (TA Instruments) was used and the experiments were conducted in an inert atmosphere (nitrogen with flow rate of $100 \mathrm{ml} / \mathrm{min}$ ). The samples $\left(5 \mathrm{mg}\right.$ ) were heated from 25 to $120{ }^{\circ} \mathrm{C}$ with heating rate of $10{ }^{\circ} \mathrm{C} / \mathrm{min}$. The enthalpies of fusion, determined as the area of melting endotherm in DSC traces, were used to calculate the degree of crystallinity of the samples $\left(X_{\mathrm{c}}^{\mathrm{DSC}}\right)$ by normalizing it to the literature value $\left(136.1 \mathrm{~J} \mathrm{~g}^{-1}\right)$ [34] for perfectly crystalline PCL and the degree of crystallinity of PCL matrix by taking into account its weight fraction in the samples.

\subsubsection{Thermogravimetric analysis (TG)}

The thermal stability of the nanocomposites and the organic content in the modified sepiolites were characterized by TG (SDT Q600 TA Instruments). Samples of around $5 \mathrm{mg}$ were heated in air $(100 \mathrm{ml} / \mathrm{min})$ from 25 to $800{ }^{\circ} \mathrm{C}$ with a heating rate of $20{ }^{\circ} \mathrm{C} / \mathrm{min}$.

\subsubsection{Melt rheology}

The rheological measurements on PCL and nanocomposites' melt at $100{ }^{\circ} \mathrm{C}$ were carried out on a Discovery Hybrid Rheometer HR2 (TA Instruments) using oscillatory shear mode. Parallel plate geometry was used with plate diameter of $25 \mathrm{~mm}$ and sample thickness of $1 \mathrm{~mm}$. The frequency applied in small amplitude oscillatory shear experiments was $0.1-100 \mathrm{rad} / \mathrm{s}$ with five points per decade on the logarithmic scale and the strain amplitude for all samples was $0.5 \%$, which was ascertained to be within the linear viscoelastic region.

\subsubsection{Dynamic mechanical analysis (DMA)}

The DMA experiments on rectangular samples $\left(40 \times 12 \times 1 \mathrm{~mm}^{3}\right)$ were performed on a Discovery Hybrid Rheometer HR2 (TA Instruments) in torsion mode with a static pre-tension of $1 \mathrm{~N}$. The temperature sweep experiments were conducted from -120 to $60{ }^{\circ} \mathrm{C}$ (with a step of $2.5^{\circ} \mathrm{C}$ ) at frequency of $1 \mathrm{~Hz}$ and strain amplitude $(0.1 \%)$ within the linear viscoelastic region.

\section{Results and discussion}

\subsection{Sepiolite modification}

The sepiolite was modified in two different ways: by covalent coupling with (3-mercaptopropyl)trimethoxysilane and by ionic exchange with protonated hexadecylamine. In Fig. 1 the powder XRD spectra of unmodified and modified sepiolites are presented. The characteristic reflections seen in native sepiolite arising from the planes (1 10 ), $(040)$ and $(400)$ at $2 \theta=7.2,19.6$ and $26.5^{\circ}$ respectively were unaltered in the spectra of the modified sepiolite. This indicates that the crystal structure was not affected by the modification. The calculated basal spacing of sepiolite from the position of (1 110$)$ reflection was $1.2 \mathrm{~nm}$ and, as expected from the non-swelling clay, it did not change with modification. The SEM images of the unmodified and modified sepiolites (Fig. 1) shows that the sepiolite typical fibrous morphological characteristics were maintained after the modification. Also it could be noticed that in the organosepiolites some disaggregation of sepiolite bundles into smaller aggregates with a fewer sepiolite needles occurred, 

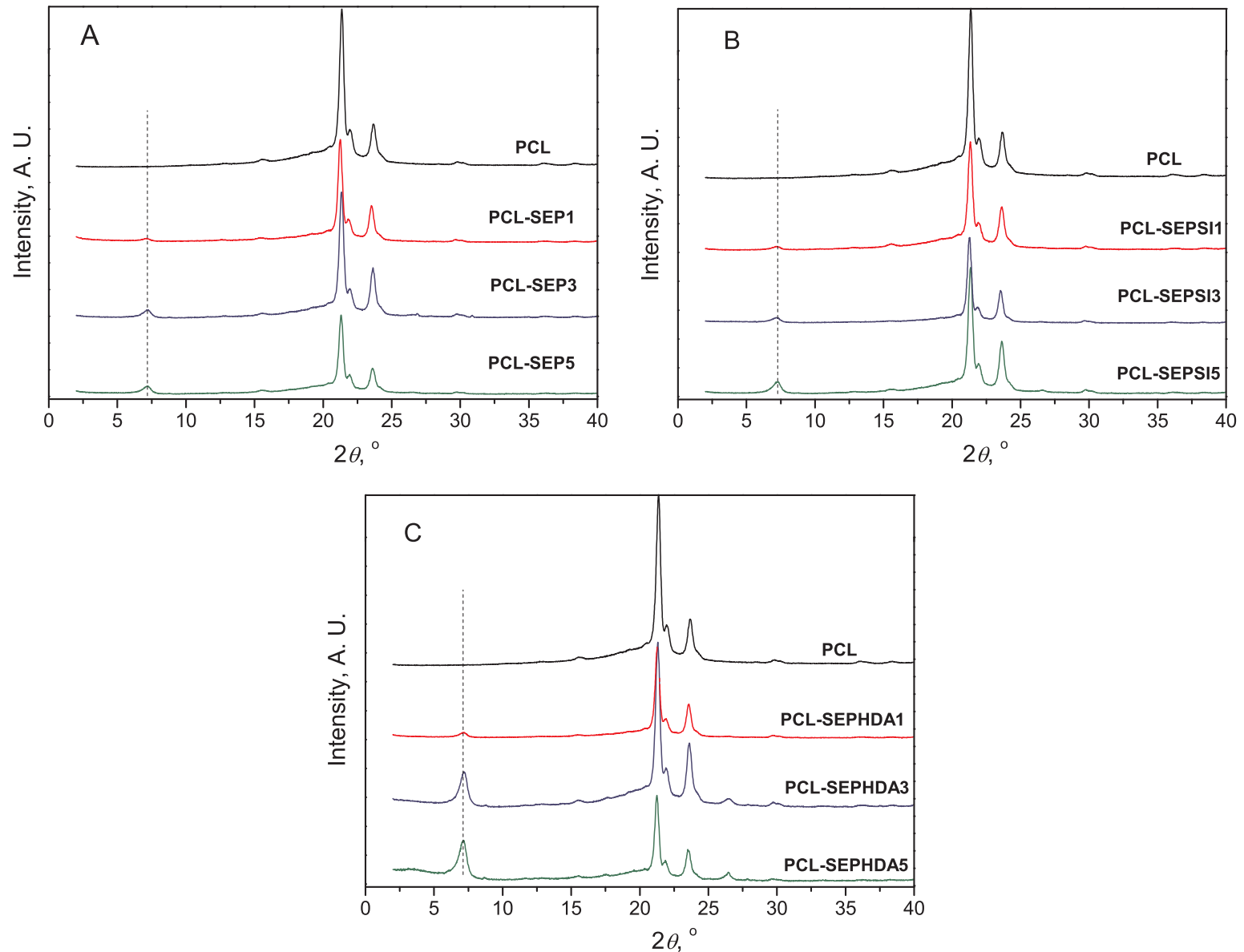

Fig. 2. XRD patterns of PCL and its nanocomposites with unmodified sepiolite (A), silane grafted (B) and HDA modified (C) sepiolite.

probably during the course of the modification procedure. A successful ionic exchange by HDA was confirmed by thermogravimetric analysis data in the air (not shown), from which it was calculated that around $12 \%$ of the modifier (based on the mass of SEP) was incorporated into the nanofiller.

\subsection{Structural and morphological characterization of nanocomposites}

In order to characterize the crystalline structure of PCL in the nanocomposites, XRD analysis was performed. The nanocomposites from all three series showed characteristic peak arising from the reflections at $\left(\begin{array}{lll}1 & 1 & 0\end{array}\right)$ plane of sepiolite positioned at $7.5^{\circ} 2 \theta$ (Fig. 2). The intensity of this peak increased with increase in the sepiolite content, without a change in its position. The diffraction pattern of PCL displayed reflections centered at 21,22 and $24^{\circ}$ arising from (lll 110$),\left(\begin{array}{lll}1 & 1 & 1\end{array}\right)$ and $\left(\begin{array}{lll}2 & 0 & 0\end{array}\right)$ planes. The PCL crystallizes in an $\alpha$-form of PCL [35] and all nanocomposites retained the characteristic crystalline structure as concluded from the presented diffractograms.

Optical microscopy was used to examine the surface morphology of the nanocomposite films. In Fig. 3 images obtained by optical microscopy of the surface of PCL and nanocomposites with $5 \mathrm{wt} \%$ of different sepiolites are presented. The images of both sides (i.e. the one in the contact with Petri glass and the other exposed to the air) of the prepared nanocomposite films were taken. The morphology of the two sides is different as reported before for polyester films obtained by solution casting $[36,37]$. The side of nanocomposite film formed in contact with glass is smooth, since the film touching the glass could not crystallize in all three directions. Therefore optical imaging of this side allowed observation of fine, lamellar spherulite structure. On the other hand, the growth of spherulites in the polymer films on the side exposed to the air was free from glass constrainment and 3D morphology could be developed with rough film surface. The PCL crystallized in the form of spherulites with characteristic lamella structure clearly observed in the image of the PCL surface which was in the contact with glass during solidification (Fig. 3A, right image). In Fig. 3A (left image) the surface of the PCL film exposed to the air during solidification is presented, where the morphology of the sample crystallized without constrains from the glass wall could be observed. With the addition of the filler the morphology was changed toward a higher number of smaller spherulites, as a consequence of nucleation effect of the added sepiolites (Fig. 3B). The spherulites fused together and their boundaries were not clearly observable any more. It appeared that the spherulites in the nanocomposites with unmodified sepiolites (PCL-SEP) had the smallest diameter, while the biggest spherulites were found in nanocomposites with silane modified sepiolites (PCL-SEPSI). Therefore, the highest nucleating effect was observed for unmodified sepiolites. It could be speculated that this was due to the poorest dispersion achieved with unmodified sepiolites, where the micron size aggregates were efficiently acting as nucleating agents. On the other hand the modified sepiolites (SEP-SI and SEP-HDA), with better dispersion in the polymer matrix, possessed less filler aggregates capable of acting as nucleating agents. Since the boundaries of spherulites could not be clearly observed it was not possible to quantitatively prove the proposed effect and to make precise difference between the two different modified sepiolites. Sepiolite aggregates of larger sizes (of the order of tens of microns) were not detected by optical microscopy inspection of the nanocomposites, which proved that the nanocomposites were successfully prepared.

In Fig. 4 representative images of cryo fractured surface of the nanocomposites are presented and compared to the PCL. The surface of 


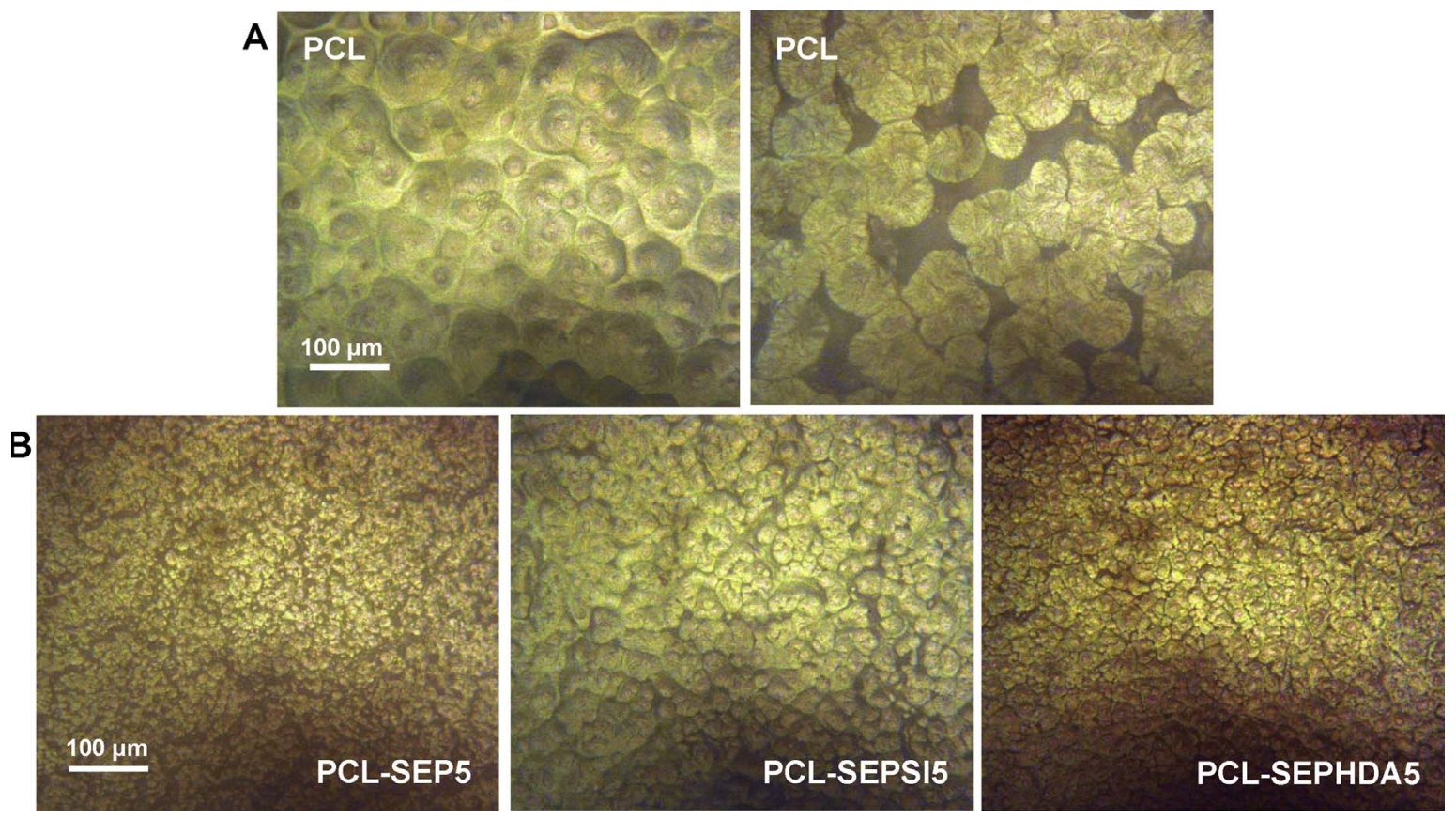

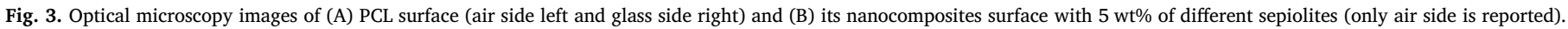

PCL was smooth and showed that a brittle fracture has occurred. In the image of nanocomposites with unmodified sepiolite (PCL-SEP3 in Fig. 4 and similar images of PCL-SEP1 and PCL-SEP5 given in the Supplementary material) single sepiolite fibers or even bundles were not easily observable. This was most likely a consequence of the poor dispersion of the unmodified sepiolite, which preferentially stayed in the form of bundles covered with a layer of polymer. The inset image with higher magnification showed the appearance of sepiolite bundle found in the PCL-SEP. In contrast, in the images of nanocomposites with modified sepiolites a uniform distribution of sepiolite could be clearly seen (bright spots in the SEM images). The content of finely distributed submicron sepiolite fibers gradually increased as the amount of the fillers increased up to $3 \mathrm{wt} \%$ of sepiolite, without detectable change in the extent of the dispersion. For the nanocomposites with the highest amount of modified sepiolites (PCL-SEPSI5 and PCL-SEPHDA5) the content of bright spots was not as pronounced as expected. This could be a consequence of some agglomeration occurring at higher content of sepiolites. The difference in the distribution of sepiolite fibers between PCL-SEPSI and PCL-SEPHDA could be hardly observed. The SEM analysis pointed to the better dispersion of the sepiolites modified with organic molecules. The presence of organic modifier not only provided better interaction between the polymer matrix and the filler, but also played a role in the better dispersability of sepiolite in chloroform, thus facilitating the enhanced dispersion in the matrix. However, from the SEM analysis the difference in the state of dispersion between the two different organomodified sepiolites could not be distinguished.

The dispersion of sepiolite into the PCL was further evidenced by TEM, the results of which are presented in Fig. 5. In the case of the samples with native sepiolite, aggregates were observed (dark spots in the images of PCL-SEP3 and PCL-SEP5 in Fig. 5). For higher content of sepiolite (PCL-SEP5) some separated sepiolite needles could also be observed, however the aggregates were the dominant form in which the filler existed in the PCL matrix. For the modified sepiolites a good dispersion of sepiolite could be observed, with a large amount of individualized needles. Some larger aggregates could also be noticed, especially for the nanocomposites with $5 \mathrm{wt} \%$ of organomodified sepiolites. In the images taken at higher magnification, random distribution and overlap of the single sepiolite needles could also be observed for the samples with organomodified sepiolites. On the contrary, for the samples with unmodified sepiolites bundles of sepiolite needles could be easily seen in the images taken at higher magnification, since that was the dominant form in which the unmodified sepiolite was present.

\subsection{Melt rheology}

Melt rheology was used to further study the state of dispersion of the filler in the polymer matrix. The storage modulus and complex viscosity frequency dependence for PCL and nanocomposite melts at $100{ }^{\circ} \mathrm{C}$ are presented in Fig. 6.

The low frequency response of the storage modulus ismore sensitive than the loss modulus to the addition of the filler. In the case of network formation from finely dispersed fillers, the liquid like response (characterized by $\sim \omega^{2}$ scaling of storage modulus) changs to solid like response, i.e. plateau in storage modulus dependence in the low frequency region appears, accompanied by prevailing of elastic over viscous response $\left(G^{\prime}>G^{\prime \prime}\right)[38,39]$. For all three series a gradual increase of the storage modulus with increase in filler content was observed, though it was more pronounced for the nanocomposites with modified sepiolites. What is usually observed in polymer filled systems is an increase of the viscosity with filler addition, followed by more pronounced shear thinning behavior. For the unmodified sepiolites a moderate increase of the viscosity was observed with increase in the SEP content, which leveled off at $3 \mathrm{wt} \%$ of SEP. For the lowest amount of SEP viscosity was even lower for the nanocomposite compared to the neat PCL. This unusual behavior was also observed in a few nanocomposite systems $[40,41]$. For the present filler-polymer system, if weak interactions are assumed, it is reasonable to presume that the not so well dispersed sepiolite caused entanglements disruption, thus lowering the viscosity of the melt. For higher sepiolite loadings the expected increase due to hydrodynamic effect was observed. For the nanocomposites with SEP-HDA a steady increase in the viscosity was observed with increase in the filler content accompanied by slow and moderate disappearance of the Newtonian plateau in the low frequency region for the higher amounts of SEP-HDA. In comparison to the SEP containing nanocomposite the ones with SEP-HDA appeared to have better dispersion of sepiolite. The nanocomposites with SEP-SI experienced the most significant change in viscosity. Not only the highest 


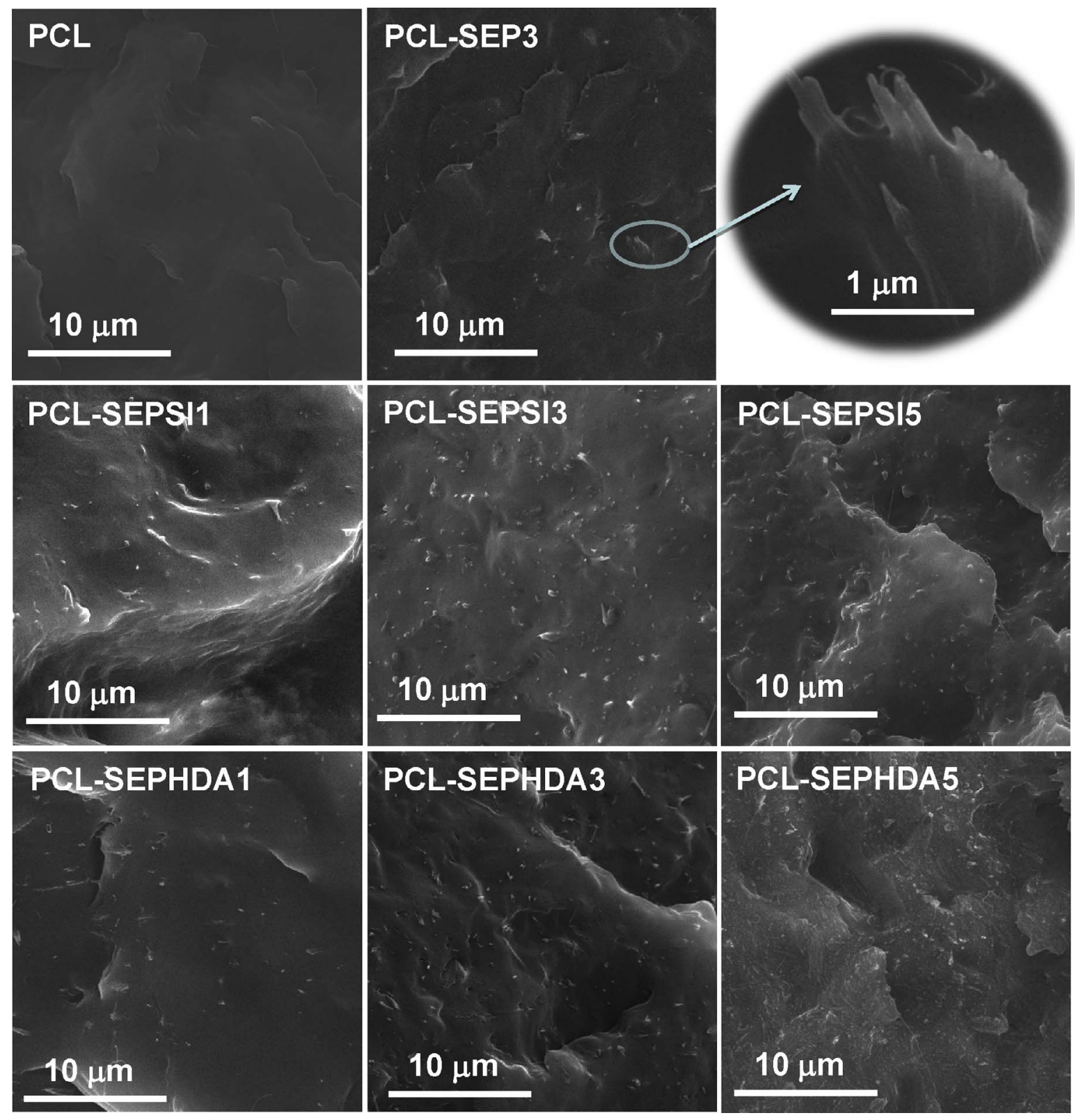

Fig. 4. SEM images of cryo-fractured surface of PCL and its nanocomposites (magnification $5000 \times$ and for the inset $50,000 \times$ ).

viscosity was recorded for PCL-SEPSI5, but also the most pronounced shear thinning, together with a disappearance of the Newtonian plateau, was observed for this sample. However, the change of the rheological parameters was not as gradual in this series as in the series with SEP-HDA. According to some analysis a formation of nanofiller network can be tracked thorough the analysis of Cole-Cole diagrams where the real and imaginary parts of some complex viscoelastic function, such as complex dynamic viscosity, are plotted against each other $[7,42,43]$. In case of homogenous polymer melt usually an arc or semicircle is observed implying the existence of relaxation time spectrum of the same origin. When there is constrain imposed by formed network, which will induce different relaxation times, a second semicircle or a tail will appear. In Fig. 7 Cole-Cole plots for PCL and nanocomposites with $5 \mathrm{wt} \%$ of different sepiolites are presented.

The PCL melt showed a single arc, which was indicative of relaxation spectrum of the homogenous melt. While the nanocomposites with unmodified and HDA treated sepiolite also showed single arc with just a hint of appearance of a tail, the nanocomposites with silane grafted sepiolite clearly showed an upward turn with rigid tail in the high viscosity region. This suggested the presence of large number of single sepiolite needles, which affected the long-range motion of the polymer matrix. The overall structure of the nanocoposites is quite complex and includes larger aggregates, bundles and single needles, the last two even might be involved in a network formation. The present set of experimental observations pointed to the better dispersion of organomodified hydrophobic sepiolites which was promoted by mediation of the hydrophobic solvent used for the preparation of the nanocomposites.

\subsection{Thermal properties and thermal stability}

The presence of filler can affect the thermal properties and degree of crystallinity, which in turn can have an impact on the processing and different properties like mechanical or barrier. In nanocomposites with modified nanosilicate melting temperatures and degrees of crystallinity can decrease, increase or they may not even be affected by the filler, therefore they have to be studied for each polymer/filler/preparation method system separately $[3,44]$. In the DSC thermograms of the nanocomposites with SEP (not shown) a single endothermic peak was 

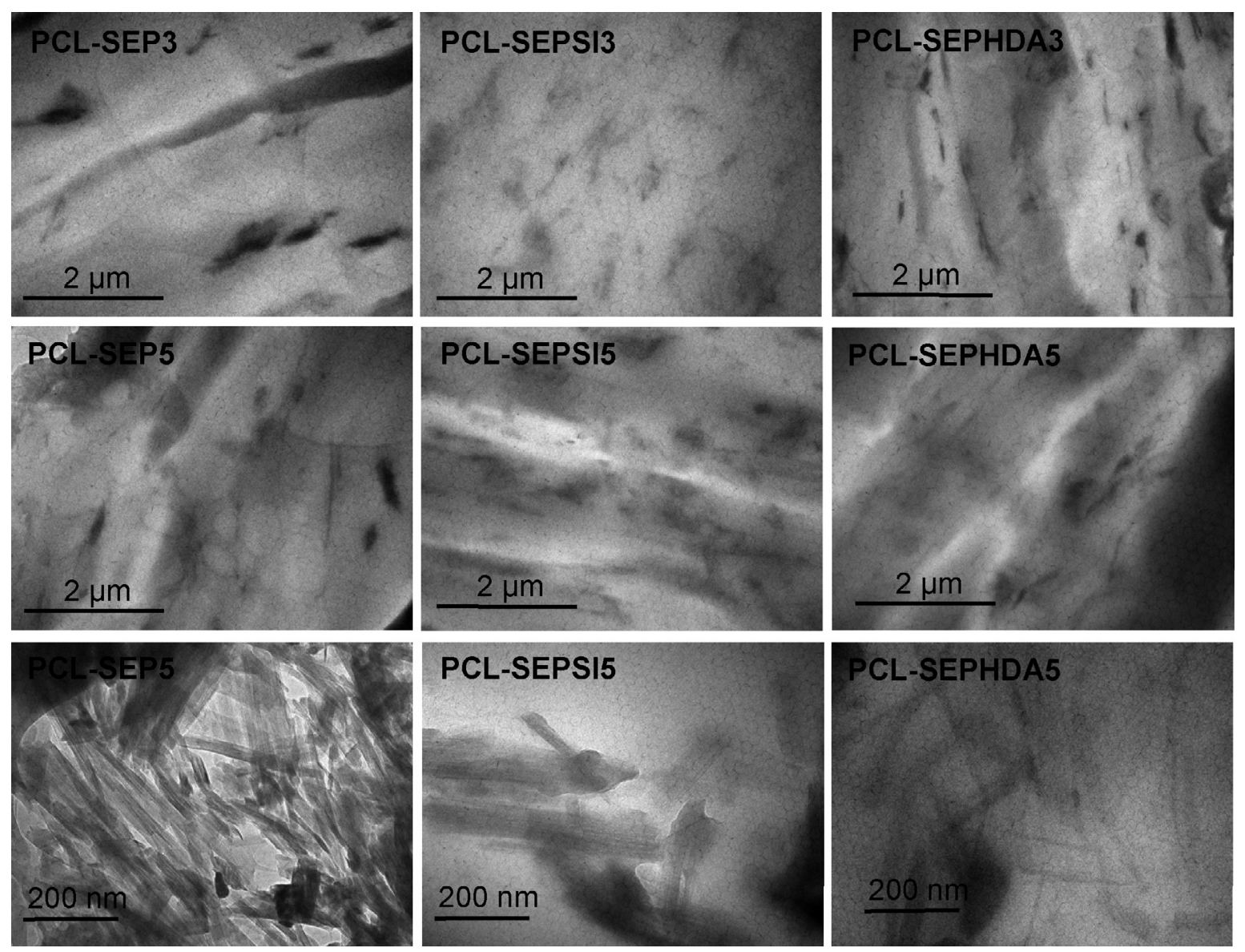

Fig. 5. TEM microphotographs of nanocomposites with 3 and $5 \mathrm{wt} \%$ of unmodified and modified sepiolites at different magnification $(6000 \times$ and $40,000 \times)$.

observed from which the melting temperatures and heats of fusion were determined (Table 1). When compared to the PCL, all prepared nanocomposites had a higher melting temperature. In the series with unmodified sepiolite the increase in the melting temperature followed the increase in the filler content. In both series of organomodified sepiolites the sample with the highest amount of modified sepiolite had the lowest melting temperature in the series. Thus the positive increment in the melting temperature was the highest for the highest loading in the case of unmodified sepiolite and for the lowest loading in the case of modified sepiolite. The increased melting temperature could be connected to the more perfect or thicker lamella formed during the growth of the spherulites.

The enthalpies of fusion (Table 1) determined from DSC thermograms were used to calculate the degree of crystallinity. All of the nanocomposite samples had lower degree of crystallinity $\left(X_{\mathrm{c}}{ }^{\mathrm{DSC}}\right)$ than PCL. The degree of crystallinity calculated from XRD the patterns $\left(X_{\mathrm{c}}^{\mathrm{XRD}}\right)$ showed the same tendency, although with more scattering of the results. The degree of crystallinity of PCL phase $\left(X_{c}(P C L)^{\mathrm{DSC}}\right)$, showing the fraction of PCL matrix crystallized in the nanocomposites, was lower in comparison to the one of PCL (48.4\%) for all of the samples. The nanocomposites with SEP showed the highest depletion of $X_{\mathrm{c}}(36.8-43.2 \%)$, followed by the PCL-SEPHDA nanocomposites (42.2-44.5\%) and the nanocomposites of PCL-SEPSI series had negligibly lower $X_{\mathrm{c}}$ (around 47\%) compared to PCL. So far investigated nanocomposites, with different sepiolites and various crystallizable polyester matrices, exhibited increased [28,31], decreased [29,30,32] or almost unaltered [17] degree of crystallinity in a reference to the neat matrix. It may be assumed that in the case of sepiolites the dispersion was not as effective as in the case of other fillers leading to decrease in the degree of crystallinity more often. The presence of filler aggregates, besides having a nucleating effect [45], as revealed by spherulite appearance in optical microscopy images, also hindered the crystallization by making a barrier to the crystal front growth. Since the highest amount of aggregates was present in nanocomposites with unmodified SEP (as revealed by SEM and TEM) the decrease in degree of crystallinity was the most prominent in this series. The samples with PCL-SEPSI most likely had the smallest amount of aggregates having the ability to interfere with the crystallization of the matrix.

The thermal stability was investigated by nonisothermal degradation experiments conducted in air. The obtained TG curves for each of the three nanocomposites series are presented in Fig. 8 and compared to the one recorded for PCL.

As expected the presence of sepiolite did not affect the mechanism of degradation of the polymer matrix. A slight difference in the thermal stability, as judged from the characteristic temperatures at which samples lost specified mass, was observed for different nanocomposites (Table 1). The temperatures at $2 \mathrm{wt} \%$ and $50 \mathrm{wt} \%$ mass loss for nanocomposites with unmodified sepiolites were lower compared to neat PCL implying lower thermal stability of the polymer matrix in the presence of sepiolite. With increase in the sepiolite content the thermal stability of PCL-SEP in the beginning stages was slightly improved. The nanocomposites with higher amount of modified sepiolites had slightly better thermal stability in the initial stages of the degradation. However, in the latter stages of the degradation, increased stability was observed only for nanocomposite PCL-SEPSI5. It is vary often found that the thermal stability of different polymer matrices is increased in the presence of clay fillers [32,46]. This is ascribed to the barrier effect of finely dispersed clay toward escape of volatile products or to the diffusion of oxygen, as well as to the char formation which has a role of insulator. However, there are also reports on the reduced thermal stability in the presence of clay filler $[17,23,47]$ as a consequence of its action through heat accumulation, catalytic activity of released metallic 

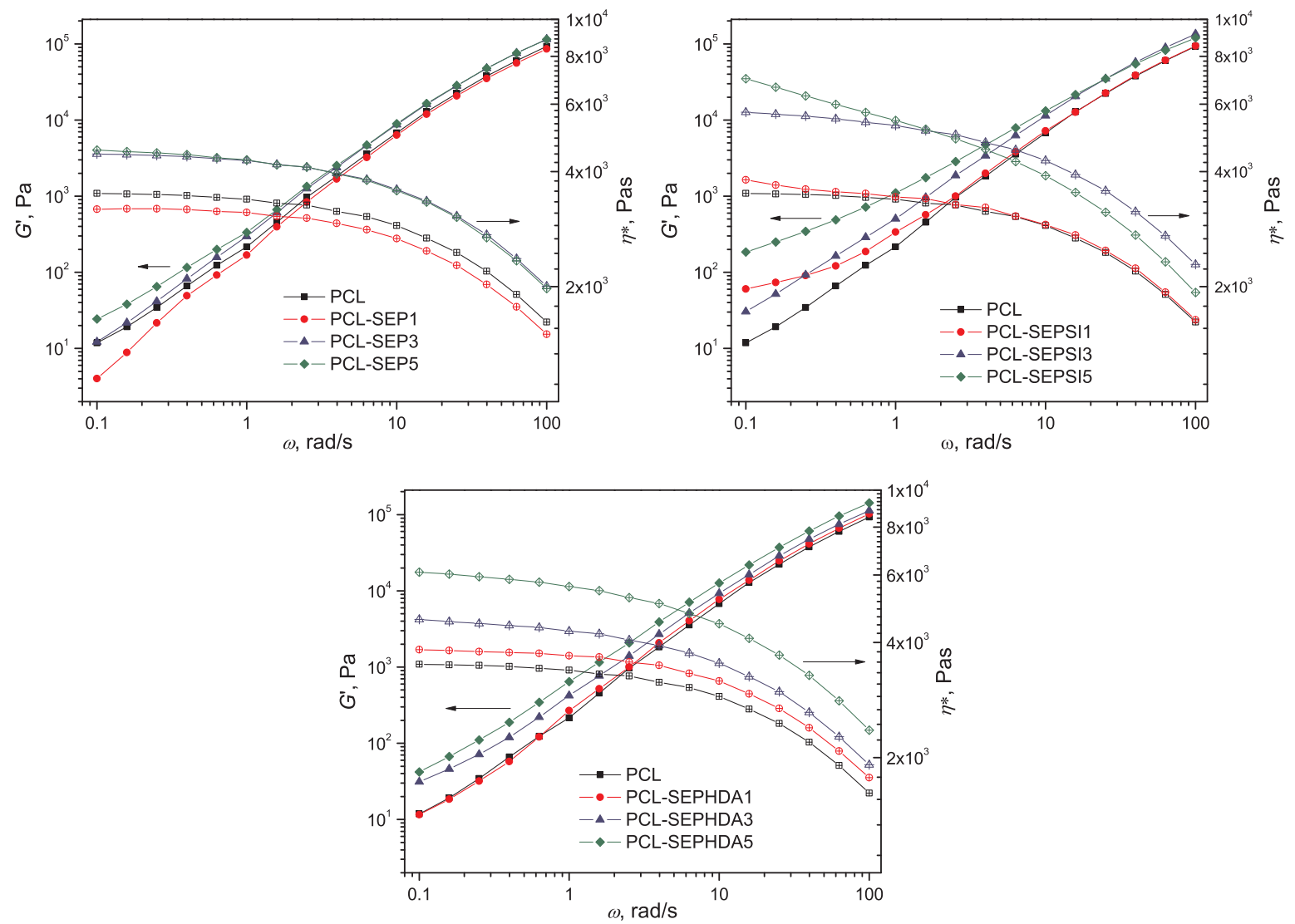

Fig. 6. Frequency dependence of storage modulus, $G^{\prime}$, and complex dynamic viscosity, $\eta^{*}$, for PCL and three series of nanocomposites at $100{ }^{\circ} \mathrm{C}$.

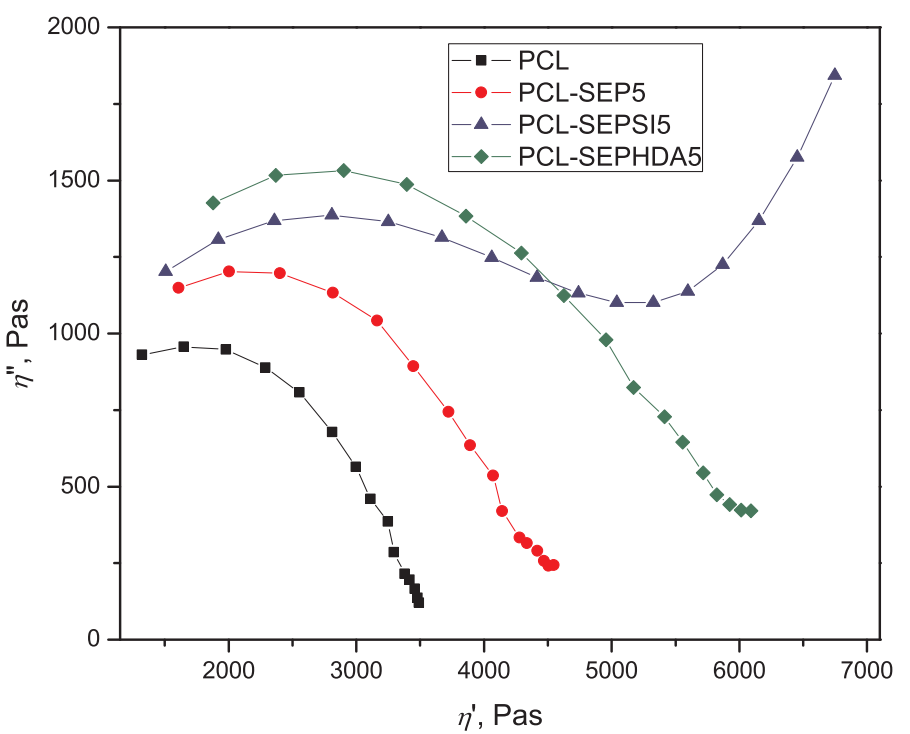

derivates, water or hydroxyl groups on its surface. In the case of organomodified sepiolites the effect on thermal degradation could be positive through the improved dispersion accompanied with increased tortuosity for the volatile products and oxygen and negative through acceleration of the degradation by the catalytic effect of the organic modifier degradation, especially in the case of amine modifiers. In the present case it could be assumed that the thermal stability was improved for the nanocomposites with organomodified sepiolites through increase in the dispersion state. Also for the nanocomposites with SEPSI the possible decomposition accelerating effect [48] from hydroxyl groups present in the bare SEP was minimized through modification
Fig. 7. Cole-Cole plots of complex viscosity components for PCL and its nanocomposites with $5 \mathrm{wt} \%$ of different sepiolites at $100{ }^{\circ} \mathrm{C}$.

reaction of hydroxyl groups and silane. For the composites with SEPHDA the slightly lower thermal stability in the initial stages compared to PCL-SEPSI might be a consequence of the catalytic action of more thermo-labile modifier degradation products.

\subsection{Dynamic mechanical analysis}

The mechanical properties of nanocomposites and temperature transitions were evaluated by dynamic mechanical analysis in temperature sweeps with fixed frequency $(1 \mathrm{~Hz})$ and deformation within linear viscoelastic range. The storage modulus, loss modulus and loss 
Table 1

Thermal properties, degree of crystallinity and TG mass loss temperatures.

\begin{tabular}{|c|c|c|c|c|c|c|c|c|}
\hline Sample & $T_{\mathrm{m}},{ }^{\circ} \mathrm{C}$ & $\Delta H_{\mathrm{m}}, \mathrm{J} / \mathrm{g}$ & $X_{\mathrm{c}}^{\mathrm{DSC}}, \%$ & $w_{\mathrm{PCL}}$, wt. $\%$ & $X_{\mathrm{c}}(\mathrm{PCL})^{\mathrm{DSC}}, \%$ & $X_{\mathrm{c}}^{\mathrm{XRD}}, \%$ & $T_{2 \%},{ }^{\circ} \mathrm{C}$ & $T_{50 \%},{ }^{\circ} \mathrm{C}$ \\
\hline PCL & 65.3 & 65.8 & 48.4 & 100.0 & 48.4 & 55.8 & 286 & 415 \\
\hline PCL-SEP1 & 65.8 & 55.3 & 40.6 & 98.8 & 41.1 & 53.7 & 264 & 395 \\
\hline PCL- SEP3 & 66.4 & 48.4 & 35.5 & 96.5 & 36.8 & 51.0 & 282 & 398 \\
\hline PCL- SEP5 & 68.1 & 55.3 & 40.6 & 94.2 & 43.2 & 47.8 & 275 & 408 \\
\hline PCL-SEPSI1 & 67.6 & 63.6 & 46.7 & 98.5 & 47.4 & 46.7 & 285 & 398 \\
\hline PCL-SEPSI3 & 67.4 & 61.3 & 45.0 & 95.6 & 47.1 & 59.6 & 300 & 411 \\
\hline PCL-SEPSI5 & 66.6 & 59.3 & 43.6 & 92.7 & 47.0 & 52.5 & 287 & 416 \\
\hline PCL-SEPHDA1 & 67.7 & 59.9 & 44.0 & 98.8 & 44.5 & 57.8 & 276 & 407 \\
\hline PCL-SEPHDA3 & 67.5 & 55.3 & 40.6 & 96.3 & 42.2 & 48.8 & 296 & 403 \\
\hline PCL-SEPHDA5 & 65.8 & 55.4 & 40.7 & 93.9 & 43.3 & 53.0 & 297 & 405 \\
\hline
\end{tabular}

factor temperature dependences are presented in Figs. 9 and 10. The PCL as well as all nanocomposites showed typical storage modulus dependence for viscoelastic polymer which, with temperature increase, went from glassy to rubbery state passing through glass transition region.

From the obtained curves, the values of storage modulus in the glassy $\left(-90^{\circ} \mathrm{C}\right)$ and rubbery $\left(30^{\circ} \mathrm{C}\right)$ region were compared (Table 2$)$. An increase in the storage modulus was observed for the nanocomposites compared to the neat matrix due to the reinforcement effect of the present rigid filler. The degrees of crystallinity calculated from DSC and XRD data (Table 1) were lower for the nanocomposites in comparison to neat matrix, which showed that the observed reinforcement could be ascribed exclusively to the presence of sepiolites. The increase in the storage modulus for the highest amount of unmodified sepiolite was

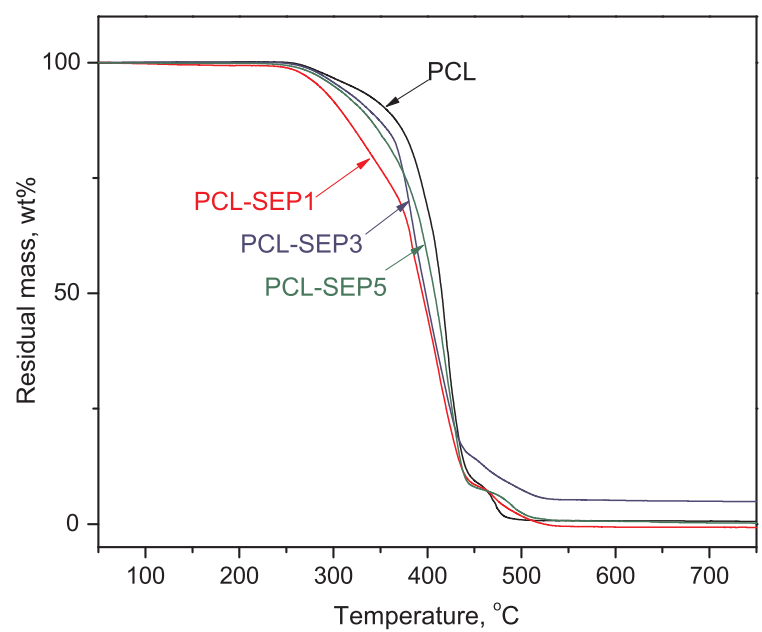

found to be $10 \%$, for silane grafted sepiolite $32 \%$ and for HDA modified sepiolite $50 \%$. The increase was more intense in the rubbery than in glassy region, which is a common behavior of filled polymer systems. The filler rigidity does not change with the change in the temperature, and its full contribution as reinforcing agent is most prominent in the rubbery plateau, when the mobility of the polymer matrix is increased above glass transition temperature. Form the values of storage modulus in the glassy $\left(G_{\mathrm{g}}^{\prime}\right)$ and rubbery $\left(G_{\mathrm{r}}^{\prime}\right)$ state, the coefficient of reinforcement was calculated for all the composites (COMP) by using the following equation $[49,50]$ :

$C=\left(G_{g}^{\prime} / G_{r}^{\prime}\right)_{\mathrm{COMP}} /\left(G_{g}^{\prime} / G_{r}^{\prime}\right)_{\mathrm{PCL}}$

The smaller values of $C$ mean higher effectiveness of the filler. The lowest values of $C$ were obtained for nanocomposites with HDA

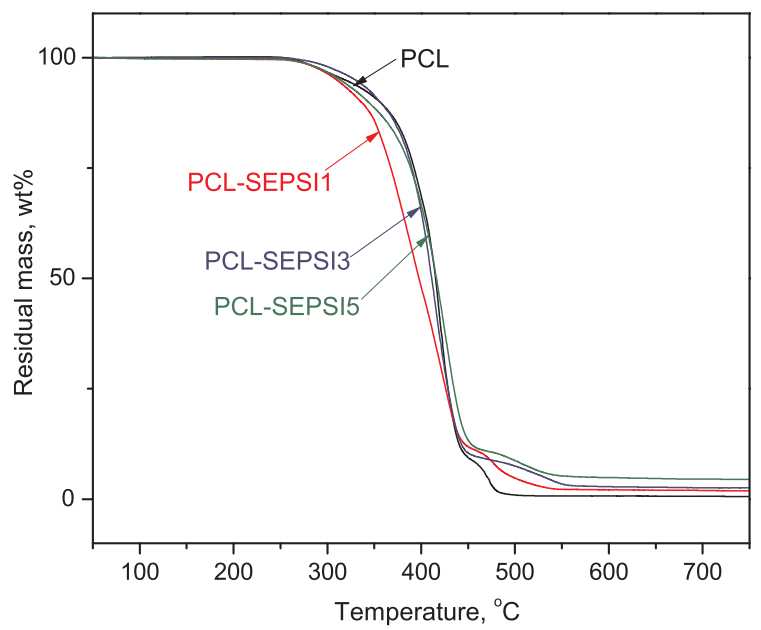

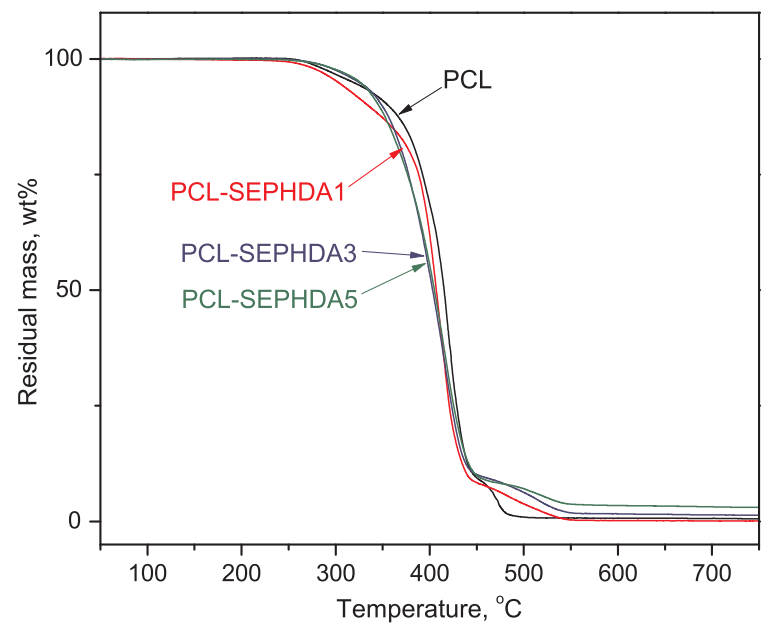

Fig. 8. TG curves obtained in air atmosphere for PCL and its nanocomposites. 

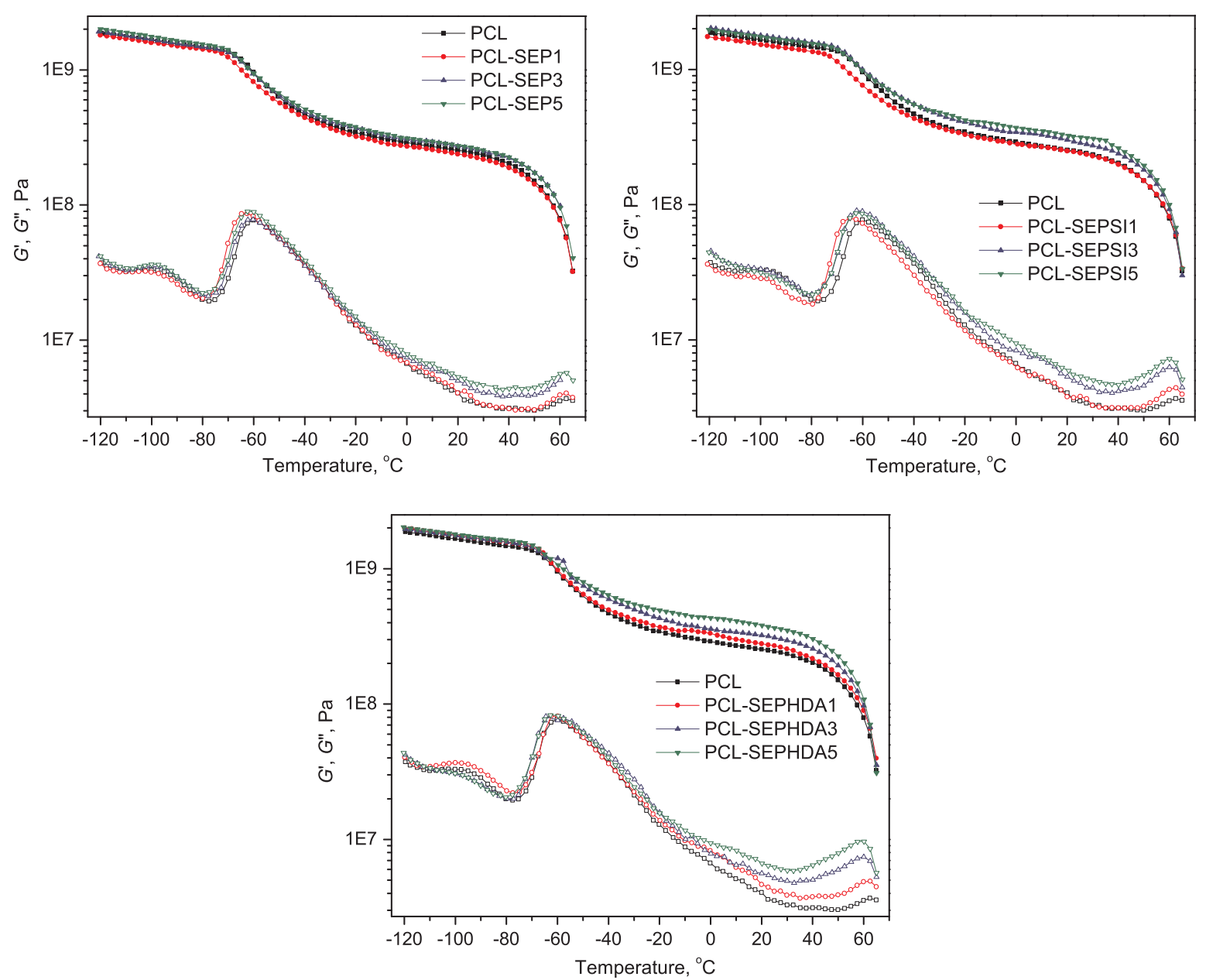

Fig. 9. Storage and loss modulus temperature dependences of nanocomposites at $1 \mathrm{~Hz}$.

modified sepiolites which also followed a decreasing trend with increase in the filler content. The reinforcement achieved by using a nanofiller depends on the level of dispersion, the size and aspect ratio of the nanofiller and interfacial interaction established with the matrix. As judged from the melt rheology of nanocomposites the best dispersion of sepiolite was achieved for silane grafted sepiolite. The reinforcement attained by silane grafted sepiolite was much higher compared to moderate reinforcement obtained by unmodified sepiolite, which was due to the better dispersion state. However, the best performance was achieved by SEP-HDA. This high reinforcement of the HDA modified sepiolite was not only consequence of the dispersion state, but also of the better interaction between the filler and the matrix.

For all of the tested nanocomposites the loss modulus (Fig. 9) and $\tan \delta$ (Fig. 10) temperature dependences were found to be similar. In the curves of loss modulus temperature dependence the most prominent difference between the three nanocomposite series was observed at temperatures near the melting of PCL. In this temperature region, a small peak, not so pronounced for PCL, became more distinct for the nanocomposites, especially for the PCL-SEPHDA series. The origin of this peak was probably from the relaxations in the PCL crystallites near the melting temperature and could indicate a collapse in the interaction between PCL and sepiolites [51].

The glass transition temperature was determined as the maximum in the $\tan \delta$ curve. The $T_{\mathrm{g}}$ values of all samples were lower compared to PCL. This indicated the absence of formation of rigid amorphous phase with reduced mobility of polymer segments, which is often noticed for nanocomposites. Stronger interaction between PCL and sepiolite would produce a constrainment onto the certain fraction of the polymer chains with an opposite shift in $\tan \delta$ peak, usually accompanied with decrease in the height and area under this peak. In Table 2. the values of the height and area of $\tan \delta$ peak, $(\tan \delta)_{\max }$ and $(\tan \delta)_{\text {area }}$, respectively are listed. It was observed that only in the SEPHDA series a small, yet continuous decrease in these values existed. This behavior indicated the better interaction between the SEP-HDA modified sepiolite and PCL in comparison to other sepiolites.

\section{Conclusion}

Nanocomposites of PCL and needle-like sepiolites were prepared under mild conditions through solvent casting. The organomodification of sepiolites was performed by grafting with short (3-mercaptopropyl) trimethoxysilane and by ionic exchange with long hexadecylamine in order to promote its dispersion in the hydrophobic PCL matrix. The state of dispersion as well as overall performance of the nanocomposites were found to be different for those with unmodified and organomodified sepiolites. The morphological characterization revealed a better dispersion of organomodified sepiolites. Also, the melt rheology data showed increased rheological parameters for nanocomposites with modified sepiolites and indicated that the best dispersion was achieved for silane treated sepiolite. In presence of sepiolites the melting temperatures of PCL matrix were increased while the degree of crystallinity was lower. It was found that the presence of native sepiolite reduced the thermal stability of PCL. The deterioration of the thermal stability was retarded for the organomodified sepiolites, as a consequence of better dispersion which provided a higher tortuosity for the volatile products. The mechanical performance of the nanocomposites was improved as the results from the dynamic mechanical analysis showed. The highest reinforcement was achieved for the sepiolites modified with 

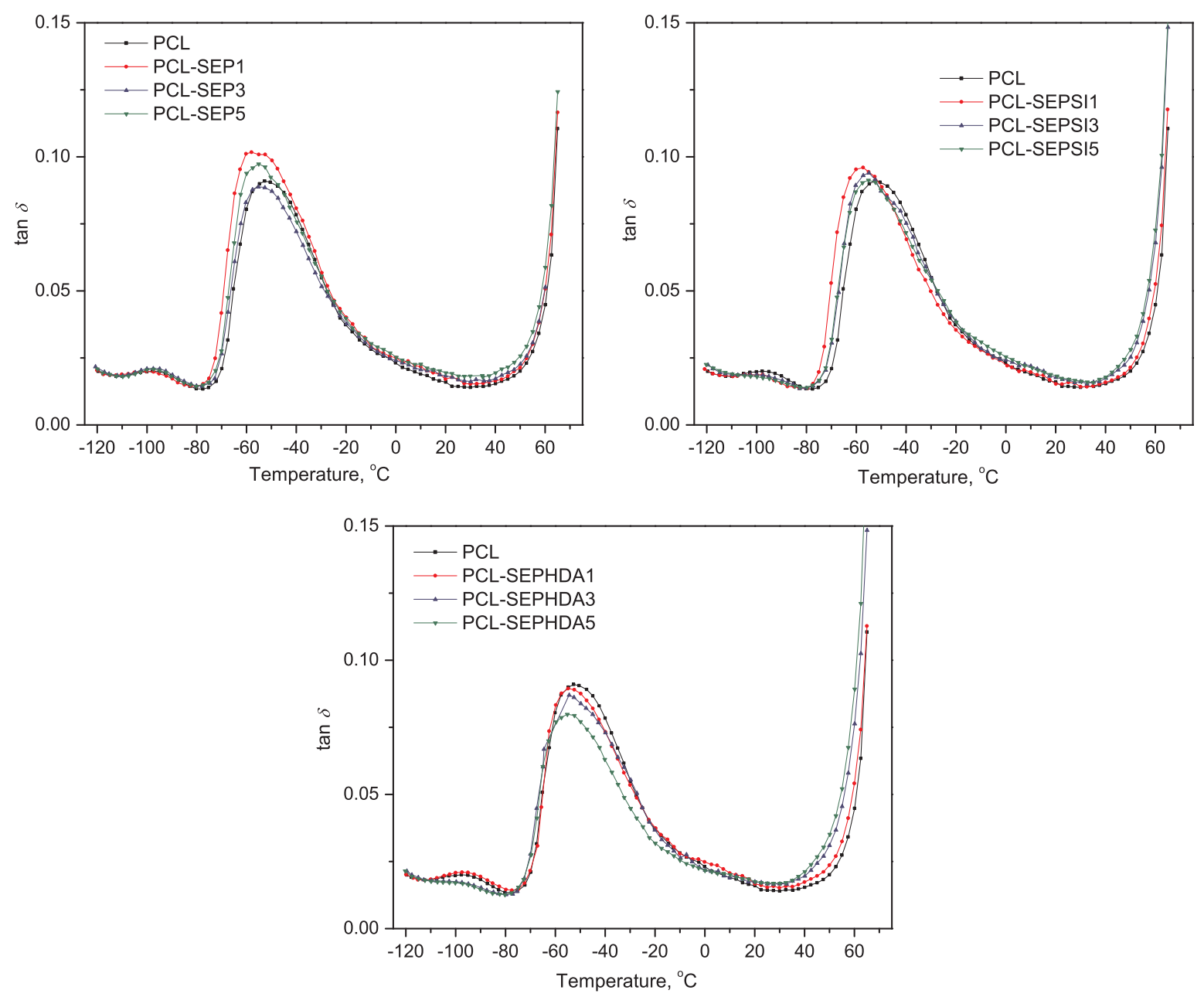

Fig. 10. Loss tangent temperature dependences for PCL and its nanocomposites.

Table 2

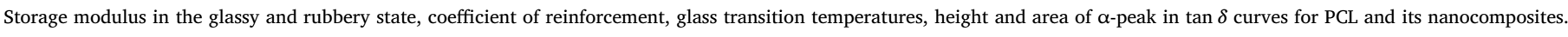

\begin{tabular}{|c|c|c|c|c|c|c|}
\hline Sample & $\left.G_{(-90}^{\prime}{ }^{\circ} \mathrm{C}\right), \mathrm{GPa}$ & $G_{\left(30^{\circ} \mathrm{C}\right)}^{\prime}, \mathrm{GPa}$ & $C$ & $T_{\mathrm{g}},{ }^{\circ} \mathrm{C}$ & $(\tan \delta)_{\max }$ & $(\tan \delta)_{\text {area }}$ \\
\hline PCL & 1.56 & 0.23 & 1 & -52.7 & 0.091 & 3.13 \\
\hline PCL-SEP1 & 1.50 & 0.22 & 1.03 & -57.9 & 0.101 & 3.68 \\
\hline PCL-SEP3 & 1.57 & 0.25 & 0.94 & -55.2 & 0.089 & 3.00 \\
\hline PCL-SEP5 & 1.65 & 0.26 & 0.97 & -55.1 & 0.097 & 3.20 \\
\hline PCL-SEPSI1 & 1.45 & 0.23 & 0.94 & -57.2 & 0.096 & 3.32 \\
\hline PCL-SEPSI3 & 1.68 & 0.27 & 0.92 & -54.9 & 0.094 & 3.25 \\
\hline PCL-SEPSI5 & 1.65 & 0.31 & 0.80 & -55.1 & 0.091 & 3.20 \\
\hline PCL-SEPHDA1 & 1.67 & 0.26 & 0.98 & -54.8 & 0.089 & 2.98 \\
\hline PCL-SEPHDA3 & 1.66 & 0.30 & 0.84 & -54.5 & 0.087 & 2.97 \\
\hline PCL-SEPHDA5 & 1.71 & 0.35 & 0.73 & -55.2 & 0.080 & 2.57 \\
\hline
\end{tabular}

hexadecylamine with long alkyl chain, which could be ascribed to the favorable interactions which could be established with the polyester matrix having a repeating unit with long aliphatic part.

The results presented in this study showed that the organomodification of sepiolites promoted the dispersion of nanofiller in the PCL matrix and could be used and further developed for preparation of improved biodegradable materials.

\section{Acknowledgement}

This work was financially supported by the Ministry of Education, Science and Technological Development of the Republic of Serbia (Project No. 172062).

\section{Appendix A. Supplementary material}

Supplementary data associated with this article can be found, in the online version, at http://dx.doi.org/10.1016/j.eurpolymj.2017.10.010.

\section{References}

[1] M.A. Woodruff, D.W. Hutmacher, The return of a forgotten polymerPolycaprolactone in the 21st century, Prog. Polym. Sci. 35 (10) (2010) 1217-1256.

[2] P. Bordes, E. Pollet, L. Averous, Nano-biocomposites: biodegradable polyester/nanoclay systems, Prog. Polym. Sci. 34 (2) (2009) 125-155.

[3] D.R. Paul, L.M. Robeson, Polymer nanotechnology: nanocomposites, Polymer 49 (15) (2008) 3187-3204.

[4] N. Moussaif, S. Irusta, C. Yagüe, M. Arruebo, J.G. Meier, C. Crespo, M.A. Jimenez, J. Santamaría, Mechanically reinforced biodegradable nanocomposites. A facile synthesis based on PEGylated silica nanoparticles, Polymer 51 (26) (2010) 
6132-6139.

[5] Y. Li, C. Han, J. Bian, X. Zhang, L. Han, L. Dong, Crystallization and morphology studies of biodegradable poly( $\varepsilon$-caprolactone)/silica nanocomposites, Polym. Compos. 34 (1) (2013) 131-140.

[6] M. Avella, F. Bondioli, V. Cannillo, E.D. Pace, M.E. Errico, A.M. Ferrari, B. Focher, M. Malinconico, Poly( $\varepsilon$-caprolactone)-based nanocomposites: influence of compatibilization on properties of poly( $\varepsilon$-caprolactone)-silica nanocomposites, Compos. Sci. Technol. 66 (2006) 886-894.

[7] D. Wu, L. Wu, Y. Sun, M. Zhang, Rheological properties and crystallization behavior of multi-walled carbon nanotube/poly(e-caprolactone) composites, J. Polym. Sci. Part B: Polym. Phys. 45 (23) (2007) 3137-3147.

[8] B. Chen, J.R.G. Evans, Poly( $\varepsilon$-caprolactone)-clay nanocomposites: structure and mechanical properties, Macromolecules 39 (2) (2005) 747-754.

[9] G. Gorrasi, M. Tortora, V. Vittoria, E. Pollet, B. Lepoittevin, M. Alexandre, P. Dubois, Vapor barrier properties of polycaprolactone montmorillonite nanocomposites: effect of clay dispersion, Polymer 44 (8) (2003) 2271-2279.

[10] K.K. Gupta, A. Kundan, P.K. Mishra, P. Srivastava, S. Mohanty, N.K. Singh, A. Mishra, P. Maiti, Polycaprolactone composites with $\mathrm{TiO}_{2}$ for potential nanobiomaterials: tunable properties using different phases, Phys. Chem. Chem. Phys. 14 (37) (2012) 12844-12853.

[11] P.A. Tran, D.M. Hocking, A.J. O'Connor, In situ formation of antimicrobial silver nanoparticles and the impregnation of hydrophobic polycaprolactone matrix for antimicrobial medical device applications, Mater. Sci. Eng. C 47 (2015) 63-69.

[12] R. Augustine, H. Malik, D. Singhal, A. Mukherjee, D. Malakar, N. Kalarikkal, S. Thomas, Electrospun polycaprolactone/ZnO nanocomposite membranes as biomaterials with antibacterial and cell adhesion properties, J. Polym. Res. 21 (3) (2014) 347.

[13] C.-W. Chiu, T.-K. Huang, Y.-C. Wang, B.G. Alamani, J.-J. Lin, Intercalation strategies in clay/polymer hybrids, Prog. Polym. Sci. 39 (3) (2014) 443-485.

[14] S. Pavlidou, C.D. Papaspyrides, A review on polymer-layered silicate nanocompo sites, Prog. Polym. Sci. 33 (12) (2008) 1119-1198.

[15] M. Alexandre, P. Dubois, Polymer-layered silicate nanocomposites: preparation, properties and uses of a new class of materials, Mater. Sci. Eng. R 28 (1-2) (2000) $1-63$.

[16] S. Sinha Ray, M. Bousmina, Biodegradable polymers and their layered silicate nanocomposites: in greening the 21st century materials world, Prog. Mater. Sci 50 (8) (2005) 962-1079.

[17] E. Duquesne, S. Moins, M. Alexandre, P. Dubois, How can nanohybrids enhance polyester/sepiolite nanocomposite properties? Macromol. Chem. Phys. 208 (23) (2007) 2542-2550.

[18] H.E. Miltner, N. Watzeels, A.-L. Goffin, E. Duquesne, S. Benali, P. Dubois, H. Rahier, B. Van Mele, Quantifying the degree of nanofiller dispersion by advanced thermal analysis: application to polyester nanocomposites prepared by various elaboration methods, J. Mater. Chem. 20(42) 9531-9542.

[19] W. Kuang, G.A. Facey, C. Detellier, B. Casal, J.M. Serratosa, E. Ruiz-Hitzky, Nanostructured hybrid materials formed by sequestration of pyridine molecules in the tunnels of sepiolite, Chem. Mater. 15 (26) (2003) 4956-4967.

[20] M. Liu, M. Pu, H. Ma, Preparation, structure and thermal properties of polylactide/ sepiolite nanocomposites with and without organic modifiers, Compos. Sci. Technol. 72 (13) (2012) 1508-1514.

[21] E. Bilotti, H.R. Fischer, T. Peijs, Polymer nanocomposites based on needle-like sepiolite clays: effect of functionalized polymers on the dispersion of nanofiller, crystallinity, and mechanical properties, J. Appl. Polym. Sci. 107 (2) (2008) 1116-1123.

[22] B. Manchanda, V. Kakkarakkal Kottiyath, G.S. Kapur, S. Kant, V. Choudhary, Morphological studies and thermo-mechanical behavior of polypropylene/sepiolite nanocomposites, Polym. Compos. (2015), http://dx.doi.org/10.1002/pc.

[23] G. Tartaglione, D. Tabuani, G. Camino, M. Moisio, PP and PBT composites filled with sepiolite: Morphology and thermal behaviour, Compos. Sci. Technol. 68 (2) (2008) 451-460.

[24] S. Xie, S. Zhang, F. Wang, M. Yang, R. Séguéla, J.-M. Lefebvre, Preparation, structure and thermomechanical properties of nylon- 6 nanocomposites with lamella-type and fiber-type sepiolite, Compos. Sci. Technol. 67 (2007) 2334-2341.

[25] E. Bilotti, R. Zhang, H. Deng, F. Quero, H.R. Fischer, T. Peijs, Sepiolite needle-like clay for PA6 nanocomposites: an alternative to layered silicates? Compos. Sci. Technol. 69 (2009) 2587-2595.

[26] D. García-López, J.F. Fernández, J.C. Merino, J.M. Pastor, Influence of organic modifier characteristic on the mechanical properties of polyamide 6/organosepiolite nanocomposites, Composites Part B 45(1) 459-465.

[27] D. García-López, J.F. Fernández, J.C. Merino, J. Santarén, J.M. Pastor, Effect of organic modification of sepiolite for PA6 polymer/organoclay nanocomposites, Compos. Sci. Technol. 70 (10) (2010) 1429-1436.

[28] K. Fukushima, D. Tabuani, G. Camino, Nanocomposites of PLA and PCL based on montmorillonite and sepiolite, Mater. Sci. Eng. C 29 (4) (2009) 1433-1441.

[29] K. Fukushima, M.H. Wu, S. Bocchini, A. Rasyida, M.C. Yang, PBAT based nanocomposites for medical and industrial applications, Mater. Sci. Eng. C 32 (6) (2012) 1331-1351.

[30] K. Fukushima, D. Tabuani, G. Camino, Poly(lactic acid)/clay nanocomposites: effect of nature and content of clay on morphology, thermal and thermo-mechanical properties, Mater. Sci. Eng. C 32 (7) (2012) 1790-1795.

[31] N. Moazeni, Z. Mohamad, N. Dehbari, Study of silane treatment on poly-lactic acid (PLA)/sepiolite nanocomposite thin films, J. Appl. Polym. Sci. 132(6) (2015) http://dx.doi.org/10.1002/APP.41428.

[32] D. Khandal, E. Pollet, L. Avérous, Elaboration and behavior of poly(3-hydroxybutyrate-co-4-hydroxybutyrate)- nano-biocomposites based on montmorillonite or sepiolite nanoclays, Eur. Polym. J. 81 (2016) 64-76.

[33] S.L.V. Marjanović, I. Janković-Častvan, B. Potkonjak, Đ. Janaćković, R. Petrović, Chromium (VI) removal from aqueous solutions using mercaptosilane functionalized sepiolites, Chem. Eng. J. 166 (2011) 198-206.

[34] L.N. Ludueña, A. Vazquez, V.A. Alvarez, Crystallization of polycaprolactone-clay nanocomposites, J. Appl. Polym. Sci. 109 (5) (2008) 3148-3156.

[35] D. Homminga, B. Goderis, I. Dolbnya, G. Groeninckx, Crystallization behavior of polymer/montmorillonite nanocomposites. Part II. Intercalated poly( $\varepsilon$-caprolactone)/montmorillonite nanocomposites, Polymer 47 (5) (2006) 1620-1629.

[36] F. He, S. Li, M. Vert, R. Zhuo, Enzyme-catalyzed polymerization and degradation of copolymers prepared from $\varepsilon$-caprolactone and poly(ethylene glycol), Polymer 44 (18) (2003) 5145-5151.

[37] L. Liu, S. Li, H. Garreau, M. Vert, Selective enzymatic degradations of poly(l-lactide) and poly( $\varepsilon$-caprolactone) blend films, Biomacromolecules 1 (3) (2000) 350-359.

[38] P. Cassagnau, Melt rheology of organoclay and fumed silica nanocomposites, Polymer 49 (9) (2008) 2183-2196.

[39] D.W. Litchfield, D.G. Baird, The rheology of high aspect ratio nanoparticle filled liquids, Rheol. Rev. (2006) 1-60.

[40] S.P. Thomas, S.A. Girei, M.A. Atieh, S.K. De, A. Al-Juhani, Rheological behavior of polypropylene nanocomposites at low concentration of surface modified carbon nanotubes, Polym. Eng. Sci. 52 (9) (2012) 1868-1873.

[41] I.T. Amr, A. Al-Amer, S. Thomas P, M. Al-Harthi, S.A. Girei, R. Sougrat, M.A. Atieh, Effect of acid treated carbon nanotubes on mechanical, rheological and thermal properties of polystyrene nanocomposites, Compos. Part B 42 (6) (2011) 1554-1561.

[42] L. Százdi, Á. Ábrányi, B. Pukánszky, J.G. Vancso, B. Pukánszky, Morphology characterization of PP/Clay nanocomposites across the length scales of the structural architecture, Macromol. Mater. Eng. 291 (7) (2006) 858-868.

[43] Y. Li, C. Han, J. Bian, L. Han, L. Dong, G. Gao, Rheology and biodegradation of polylactide/silica nanocomposites, Polym. Compos. 33 (10) (2012) 1719-1727.

[44] C. Harrats, G. Groeninckx, Features, questions and future challenges in layered silicates clay nanocomposites with semicrystalline polymer matrices, Macromol. Rapid Commun. 29 (1) (2008) 14-26.

[45] A.A. Vassiliou, G.Z. Papageorgiou, D.S. Achilias, D.N. Bikiaris, Non-isothermal crystallisation kinetics of in situ prepared poly( $\varepsilon$-caprolactone)/surface-treated $\mathrm{SiO}_{2}$ nanocomposites, Macromol. Chem. Phys. 208 (4) (2007) 364-376.

[46] L. Martino N.l. Guigo, J.G.l. van Berkel, N. Sbirrazzuoli, Influence of organically modified montmorillonite and sepiolite clays on the physical properties of biobased poly(ethylene 2,5-furandicarboxylate), Compos. Part B, 1102017 96-105.

[47] X. Yuan, C. Li, G. Guan, Y. Xiao, D. Zhang, Thermal degradation investigation of poly(ethylene terephthalate)/fibrous silicate nanocomposites, Polym. Degrad. Stab. 93 (2) (2008) 466-475.

[48] K. Chrissafis, G. Antoniadis, K.M. Paraskevopoulos, A. Vassiliou, D.N. Bikiaris, Comparative study of the effect of different nanoparticles on the mechanical properties and thermal degradation mechanism of in situ prepared poly( $\varepsilon$-caprolactone) nanocomposites, Compos. Sci. Technol. 67 (10) (2007) 2165-2174.

[49] L.A. Pothan, Z. Oommen, S. Thomas, Dynamic mechanical analysis of banana fiber reinforced polyester composites, Compos. Sci. Technol. 63 (2) (2003) 283-293.

[50] L. Mancic, P.I. Pontón, S. Letichevsky, A.M. Costa, B.A. Marinkovic, F.C. Rizzo, Application of silane grafted titanate nanotubes in reinforcing of polyamide 11 composites, Compos. Part B 93 (2016) 153-162.

[51] G. Jimenez, N. Ogata, H. Kawai, T. Ogihara, Structure and thermal/mechanical properties of poly ( $\varepsilon$-caprolactone)-clay blend, J. Appl. Polym. Sci. 64 (11) (1997) 2211-2220. 